\title{
OCEAn Science Instrumentation Development at the National Science Foundation: A STATUS REPORT
}

\author{
By H. Lawrence Clark
}

\section{The focus was on}

research more than

new tools to

accomplish it.
CEAN SCIENCE instrumentation and technology development are supported at the National Science Foundation (NSF) by a variety of sources. including a special program area initiated in fiscal year 1982 (FY82) specifically for this purpose. The source of support depends on the type of instrument being proposed. the specificity of its intended use. and its cost. Funding for the development of general purpose, multi-disciplinary instruments has increased by a factor of five between FY82 and FY89, while requests for funding have increased by more than a factor of twenty-five (Fig. 1). The initiation and management of the instrumentation and technology development program area has been in response to community needs that are often disparate and evolutionary as technology and ocean scicnce progress. Communication with the community and between the various federal programs that support technology development remain essential.

Ocean science research support at NSF is divided between the two sections of the Ocean Sciences Division (OCE). The four programs of the Ocean Sciences Research Section (OSRS) fund basic research activities within the four primary ocean science disciplines: Biological. Chemical. Physical Oceanography, and Marine Geology and Geophysics. Programs of the Oceanographic Centers and Facilities Section (OCFS) have diverse responsibilities. The Ocean Drilling Program supports the research drillship Joides Resolution and related activities of the international program in scientific ocean drilling. The Ship Operations and Facilities Programs provide institutional support for that part of the operation. maintenance and outfitting of the academic research vessel fleet that is necessary to support NSF-sponsored research activities. The Oceanographic Technology (OT) Program funds the acquisition of commercially available shared-use research instrumentation, as well as the development of new instrumentation and technology by individual investigators. The instrumentation development activities in OCFS were started in FY82 in response

H. Lan rence Clarh, Program Manager. Oceanegraphic Technology Program. National Sciened Foundation, $1800 \mathrm{G}$ Street. N.W.. Washington. DC 20550). to perceived needs of the academic ocean science community.

Identified Need for Instrumentation Development

In 1981, the Office of Technology Assessment (OTA) reported that technology development across the federal ocean programs was poorly coordinated and was provided mainly through specific objectives of mission-oriented agencies such as the Navy. NOAA, and NASA (OTA, 1981). The NSF wals shown to have a minimal role in ocean instrumentation and technology development. Research programs were attributed to whatever technology support was provided on an ad hoc basis.

Observers of the NSF ocean science peer review process also noted that in matching available resources to highly rated proposed research support budgets, instrumentation development was one of the first items to be cut out. The focus was on research more than new tools to accomplish it. This was especially true of instrumentation that might be generally classed as multidisciplinary. Funding pressures and the conservative nature of the peer review process forced NSF ocean technology development for many basic research applications to either be essential for the accomplishment of the highest rated research projects, or that it be done at near zero cost. or be funded elsewhere.

Given these somewhat subjective observations, an experimental program area was established in FY82 to consider proposals to develop new instrumentation useful to the types of basic research projects sponsored by OCE. In keeping with the multi-user facility responsibilities of OCFS, guidelines emphasized data collection and general use instrumentation.

\section{Review Considerations}

Ocean science instrumentation development proposals are normally mailed out for peer review. They may also be discussed during a regularly scheduled OSRS panel meeting. Reviewers are selected to cover two major proposal requirements: technological or engineering quality and ocean science relevance. Bimodal ratings occasionally result when scientists are enthusiastic about a proposed measurement capability but engineering reviewers judge that the proposal is technically flawed. The inverse case 


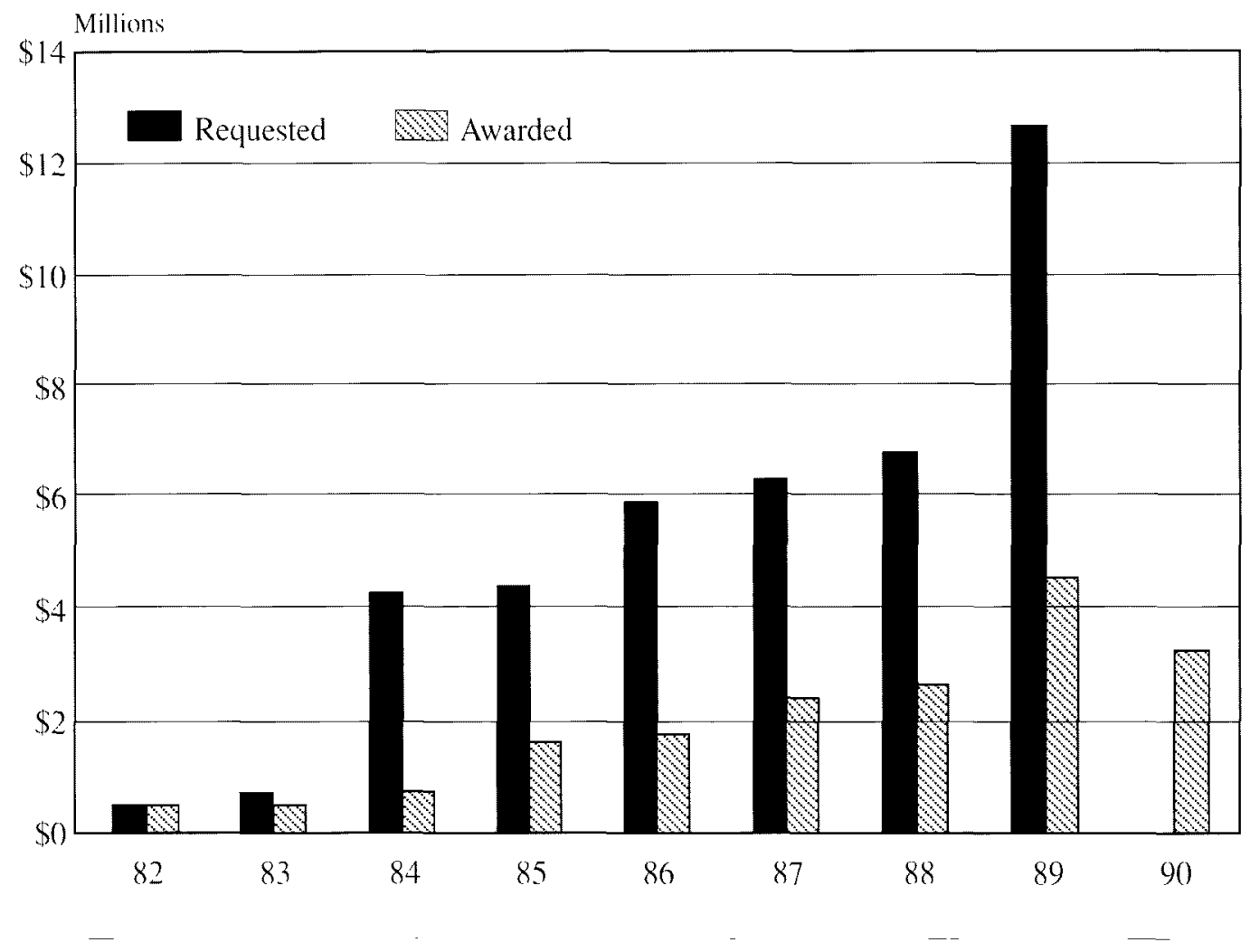

No disciplinary area

is considered higher priority than another.

Fig. I: NSF Oceanographic Technology Program's instrumentution development during FY82-FY89. (FY89 is estimated: $F Y 90$ is prejected.)

also occurs wherein some proposed new development is well-reviewed from the technical side, but the science reviewers find the critical link to batsic ocean research applications inadequate.

Judging a proposal's scientific relevance is an interesting issue. Some research projects require the development of a new instrument in order to accomplish specific research goals. Use of this instrument. while highly relevant to the project itself", may have little utility elsewhere. Development of such instrumentation is the responsibility of the sponsoring research program. At the other extreme are projects to devclop new tools and techniques for broad segments of the ocean science community. Enhanced conductivity-temperature-depth (CTD) sensors. various tethered and untethered vehicle systems, and advanced water sampler systems are three examples of general purpose tools that are clearly applicable to OCFS facility funding. Intermediate to these examples are many "gray" areas where joint consideration may be appropriate.

\section{Diversity of Subject Areas}

Instrument-development funding has been made available for applications within disciplines (sediment traps, pressure sensors, sound sources. flow cytometry) and for projects that demonstrate a potential usage beyond an immediate research application (electromagnetic field sensors, bio-optical instrumentation, current meter upgrades).

Since the development program area was set up to consider proposals for multidisciplinary projects, it is gratifying to sec that the largest percentage of proposals submitted hetween FY8t and FY89 cut across disciplinary lines (Fig. 2, p. 24). The distribution of funded projects is about the same as for proposed projects. No disciplinary area is considered higher priority than another. Proposals generally have not been solicited. The only exception might be for classes of new or improved instrumentation that have been identified as a high priority during the planning stages for major global geoscience initiatives such ats WOCE. GOFS. and RIDGE (see appended list for acronyms).

Despite the diversity in observational needs between ocean science disciplines, three general categories of instrument development projects can be identified. reflecting different community requirements:

- Demonstration projects: This category represents the greatest number of proposals with the most modest budgets. They typically seek part-time support for a technician or engineer plus supplies to test an idea for enhancing existing instrumentation. Examples include development of shipboard data logging sys- 


\section{Getting a strong}

peer consensus on a

complex development

proposal is difficult. tems. trial of a new but as yet untested microprocessor, and a feasibility test of a technology developed in another field. These projects have readily achievable goals within a finite period of time. Completed projects have resulted in published papers in peer reviewed joumals, and others in follow-on implementation projects.

- Implementation projects: This category represents a range of activities to make a full-scale test of a new instrument or technology or to implement modifications to existing systems. These are normally multiyear projects where the observational parameters, data types, and feasibility of implementing the technology have been demonstrated. Proposed projects can be considered through the implementation and validation stages. Once the instrument s utility has been demonstrated and it is used for research, its operation and enhancements are the research program 's responsibility.

- Instrumentation systems development: As observational requirements expand over lime and space scales and research becomes more interrelated and multidisciplinary, there have been increased requirements for instrumentation systems development. These major projects are represented by cooperative efforts between scientists and engineers to integrate several instruments and technologies into an observational system. Parallel advances in theory and instrumentation are usually necessitated. Bioacoustic and satellite remote sensing. long-term moorings, tomography, conditional sampling devices built around knowledge-based systems, and fiber optic sensors are examples of this complex category of development project. A long-term effort is required at relatively high annual cost. and risk of failure is a further consideration.

The NSF peer review system has not lent itself especially well to long-term systems development. Most major ocean science technology advances have been sponsored by long-term mission agency initiatives. Peer review works best in selecting the most meritorious research proposals where a hypothesis. research approach, and anticipated advances may be succinctly proposed and assessed. Getting a strong peer consensus on a complex development proposal is difficult. Even when reviewers agree with the goals and the technical plan. the time span, risk, and costs for gaining these potential future benefits may represent a larger investment than the year-by-year funding process easily accommodates. Instrumentation-development program managers must join peer reviewers in decision-making. Resolving differing reviewers opinions and balancing risks of failure against potential benefits for the research community entail a more global perspective than a consensus of independent reviewers may provide.

\section{Ocean Engineering}

Ocean engineering has received increased attention at NSF during the past several years, particularly within the Engineering Directorate. Distinctions hetween ocean engineering and ocean science tech-

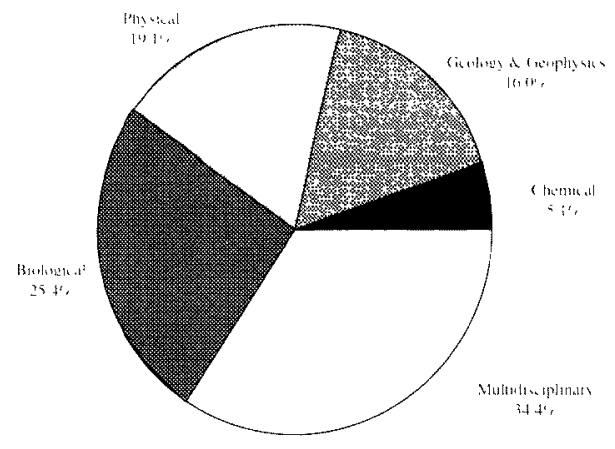

Fig. 2: Distribution of 256 instrumentation development proposals by discipline during FYSt-FYS9.

nology development are frequently vague. Programs within the Geosciences and Engineering Directorates have identified specific interests and areas of responsibility. A joint announcement was published and circulated in 1988 entitled "Ocean Engineering and Technology at the NSF" (\# NSF-88-125). Program descriptions, areas of interest. and guidelines for proposal submission are consolidated in one brochure.

The joint announcement has been valuable in addressing a congressional mandate in FY89. An eleventh-hour amendment to the NSF appropriation bill directed NSF to "support enhanced research efforts in Ocean Engineering with a focus on the Pacific Basin." In response to this directive. \$2 million was taken off the top of the Ocean Sciences Division budget to augment technology development activities of the Oceanographic Technology Program. The Engineering Directorate will also fund at least $\$ 1$ million through a new Ocean Engineering Initiative. Guidelines to be followed in considering proposals are those already spelled out in the joint announcement.

Earmarked funds have mixed benefits. While it is gratifying for some to have a favorite interest recognized and enhanced, congressional interests don t always match community priorities and needs ( Shaw. 1989). Enhancing ocean engineering and technology development for one year does little to meet the demonstrated long-term efforts required to make advances in this field. (The reduction in projected funding between 1989 and 1990 in Fig. 1 assumes the one-year ocean engineering mandate will not be renewed and available funds will revert to base levels.)

\section{Priority for Growth}

Ocean scicnce instrumentation and technology development remain a priority for growth within OCE. It's generally acknowledged that there is insufficient funding to support well-reviewed and high 


\begin{tabular}{|c|c|}
\hline \multicolumn{2}{|l|}{ Creosciences Directorate: } \\
\hline Oceanographic Technology Program & 54.50 m millon \\
\hline Ocean Drillng Program & 2.15 million \\
\hline Ocean Scicnee Research Programm & 2.67 million \\
\hline Division of Polar Programs & 0.45 million \\
\hline Enginexring Directorate & $3 .(0)$ million \\
\hline Total & $\$ 12.77$ million \\
\hline
\end{tabular}

Table 1: Estimated Fys9 sapport for ocean engineering and oceanographic technology at NSF.

priority research projects, not to mention basic instrumentation necessary to conduct this research. Based on this, some argue that funds to develop new instrumentation could be better spent elsewhere. However, progress in ocean science research depends on increasing our observational capabilities of the ocean and its processes. Mechanisms must be in place to consider instrumentation and technology development if we are to continue to make advances in ocean science research. A sustained and increasing level of effort is needed to encourage and foster technological advances that will benefit ocean science research activities.

It is difficult to assess the impact of OCE: technology development activities to date. Unlike space exploration. most advances in ocean science come in small incremental steps rather than spectacular achievements. The program has effectively met a community requirement for supporting modest projects to enhance and upgrade existing observational and analytical research capabilities. The availability of significant levels of funding for long-term development of new instrumentation and technology should remain a priority for growth. Provision of these funds for instrument development must be balanced against research and facility requirements.

A major challenge for the future is communications. Better communications is required between ocean scientists, engineers and technicians for transferring new technologies to the scientific users. Communications is also required between various national and international organizations that sponsor promote and monitor ocean science and engineering activities. Given the diversity of ocean science, important roles exist for federal mission agencies, private and state research institutions. industry and individuals. The health and vigor of ocean science research activities partially depends on advancing observational capabilities that are driven by new developments in instrumentation and technology.

\section{Acronyms}

NOAA. National Oceanic and Atmospheric Administration: NASA, National Aeronautics and Space Administration; WOCE. World Ocean Circulation Experiment; GOFS, Global Ocean Flux Study. RIDGE is not an acronym but refers to a program designed to sludy crustal spreading centers at midocean ridges.

References

OTA: Office of Technology Aswessment. 1981: Te hmolosy and

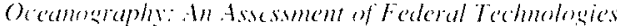
for Octanographere Rescarch and Montoring. U.S. Government Printing Office. $161 \mathrm{pP}$

Shan. George H.. 1989: Editonal: Priontic in Science Fundmg. LO(1), 70/6).529.

\section{Disclaimer}

Any opinions, findings, conclusions or recommendations expressed in this article are those of the author and do not necessarily reflect the views of the National Science Foundation. コ

\section{Earmarked funds}

have mixed benefits. 